\title{
Economic and Social Impacts of Khat (Catha edulis Forsk) Chewing Among Youth in Sebeta Town, Oromia Ethiopia
}

\author{
Muluneh Bekele Etana \\ Department of Horticulture, College of Dry-Land Agriculture, Samara University, Afar, Ethiopia \\ Email address: \\ muluneh.b2002@yahoo.com

\section{To cite this article:} \\ Muluneh Bekele Etana. Economic and Social Impacts of Khat (Catha edulis Forsk) Chewing Among Youth in Sebeta Town, Oromia \\ Ethiopia. Biomedical Statistics and Informatics.Vol. 3, No. 2, 2018, pp. 29-33. doi: 10.11648/j.bsi.20180302.14
}

Received: July 6, 2018; Accepted: July 17, 2018; Published: August 16, 2018

\begin{abstract}
Khat (Catha edulis Forsk) is a large green shrub grown in Eastern to Southern Africa and extends to Arabian Peninsula. The leaf of Khat comes from a small evergreen shrub that can grow to the size of a tree. Both young buds and tender leaves are chewed to attain a state of euphoria and stimulation. Khat leaves contain Cathinone which it's an active brain stimulant and Khat ingestion in low doses results in decreased appetite, euphoria, increased intellectual efficiency, and hyperalertness.High doses and chronic use of Khat can cause more serious adverse neurological, psychiatric, cardiovascular, dental, gastrointestinal and genitourinary effects. Besides damaging health, Khat chewing has adverse socio-economic consequences effects on many other aspects of life. It has its own impact on mental and physical health of the chewers. This study was conducted from September to June 2017 using both quantitative and qualitative methods of data collection. A total of 250 samples were included in the study. Structured questionnaire were employed during data collection with the main objectives of to assess the socio-economic effects of Khat chewing among youth of Sebeta town, Oromia, Ethiopia. The studies revealed that Khat chewing was associated with carelessness, frequent absenteeism from working place, poor academic performance of chewer students, poor interaction with the societies, depression and anxiety, poor confidence, exposed for economic problem, health problems, conflict in the family. Generally, the current Khat chewing practices in the study area are relatively high. So efforts like creating awareness about negative effects, making different recreation methods available, addressing the underlying social problems of unemployment, poor housing, and cultural alienation and promote positive measures for community development and develop a health education program to raise awareness and formulating common conventions regarding Khat use mainly by young generations are necessary to decrease the magnitude of chewing practices and thereby its associated consequences.
\end{abstract}

Keywords: Economy, Impacts, Khat Chewing, Social, Sebeta, Youth

\section{Introduction}

The estimate of the number of people chewing Khat globally ranges from 5 to 10 million people. Its use may result in a variety of effects due to the different compounds in it with effects on the gastro-intestinal system and nervous system being the principal ones. The earliest reference to Khat (Catha edulis Forsk) appears to have been made around 973-1053 A.D by Al-Biurni, who meticulously compiled information on all contemporary drugs and what he called Khat, an import from Turkistan. It was used to relieve biliousness and cool the stomach and liver [1].

It was brought over 700 years ago to Yemen, where it was chewed by merchants to relieve boredom. The historical backgrounds of the origin of Khat, its composition and action, pattern and extent of use, and psycho-physical and social effects, have been reviewed elsewhere [2, 12, 14]. The earliest scientific report on Khat presented in the western world, in contrast to opium and cannabis, stated that it produced a mild form of antisocial behavior and was more akin to amphetamine or caffeine-type substance.

Khat originated in Ethiopia and spread through Kenya, Somalia, Djibouti, Uganda, Tanzania, Zimbabwe, Zambia, South Africa, and Yemen. Young buds and tender leaves are chewed to attain stimulation and a state of euphoria. Although Khat is freely obtainable in these regions, its use in western countries such as the United Kingdom, Canada, and 
the United States has recently become restricted, and is now classified as a controlled substance of abuse. Nonetheless, people from Somalis and Yemenis continue the habit even after immigration to the West. Khat has other names and spellings: Khat, kat, chat, quat, catha, tschat, miraa, African salad, African tea, Abyssinian tea, kuses-salahin, and tohai. The leaf comes from a small evergreen shrub that can grow to tree size $[3,13,15]$.

The international organizations were confronted with the problems associated with Khat. Significant efforts and progress have been made since then to understand the pharmacology of Khat. The World Health Organization played an important role early on in encouraging and funding scientific studies designed to understand the active constituents of Khat and the health problems associated with its use. Because of their efforts, we now understand the pharmacology of Khat and the attendant health and human problems with its use.

Khat is banned in Saudi Arabia, Egypt, Morocco, Sudan and Kuwait [5]. With the increasing migration of people from Khat cultivating areas, it has arrived in the west and cases of Khat-induced psychosis are now recognized. It is banned in the US and some European countries. Its importation is controlled in Australia under the Customs Regulations. As a general, currently Khat chewing practices in the study area are relatively high and it needs the efforts and attentions of all concerning bodies.

\section{Literature Review}

\subsection{Social Impacts of Khat Chewing in Ethiopia}

Khat chewing is a common habit in East Africa, South Saudi Arabia, Yemenis and including Ethiopia. This habit involves picking tender leaves of Khat, putting them into one side of the mouth, chewing for a while and storing the chewed leaves in the same side of the mouth to get psychostimulation effect in the form of euphoria and excitement resulting from the cathinone contents. In the traditional social setting, the chewers meet in a house some time after mid-day, usually bringing their own supplies. The chewers lean on three or four specially made large cushions. Each side of the room accommodates six to ten persons, and occasionally up to twenty. They set up one or two communal tobacco pipes or 'Shisha'. During these Khat sessions, drinks such as cocacola, weak black tea, milk, or just cold water are available.

The guests are welcomed and carefully seated according to their social position. They then begin to masticate the leaves thoroughly one at a time while they engage in discussions and social interactions. During these sessions, the leaves and the bark of the plant are chewed slowly over several hours and the juice of the masticated leaves but not the residue is swallowed $[6,10,11]$.

After the Khat leaves are chewed, the guests stay on for most of the afternoon, engaged in animated discussions often on matters of general interest, such as community affairs. From this point of view, Khat can be seen as a means of promoting social interaction. Besides these traditional forms of consumption, Khat is nowadays also chewed by individuals idling on streets in Ethiopia, Europe and others where it is accompanied sometimes by the consumption of alcoholic beverages and other drugs at gatherings without the restraint.In Ethiopia, particularly in the study area Khat chewingis commonly used in social gatherings just as alcohol consumption is used in the west. During the last campaign in Somalia, against the use of Khat, some writers used it to help them prepare anti-Khat articles.

\subsection{Economic Impacts of Khat Chewing in Ethiopia}

Prior to the expansion of the Khat trade, coffee was the biggest crop in Yemen and Ethiopia [4]. Yemeni coffee trade peaked in the $17^{\text {th }}$ and $18^{\text {th }}$ centuries, but began to decline as a result of the competition of coffee production in Indonesia, South America, and East Africa. Now, as a result of national and regional demand, Khat is replacing a coffee crop which is similar with that of Ethiopia. Currently, in Yemen, estimates suggest that one-half to two-thirds of their arable land is being used for the cultivation of Khat, largely because farmers earn five times as much for Khat as for other crops, including coffee. Khat is also Ethiopia's fastest growing export. In Ethiopia, over 93,000 hectares of lands are devoted to Khat production, the second largest cash crop in terms of land area [7, 10, 16].

Khat chewing may harm the economy by the loss in production as a result of laziness and absenteeism. Workers go to lunch and engage in Khat sessions, and do not return to work. A current estimate suggests that over 10 billion hours of work a year were lost as a result of the Khat habit. This claim is widely disputed now. Generally, an increase in taxes is successful in reducing the use of such substances as nicotine, but surprisingly, the Yemenis paid these taxes and continued their habit. Khat is also cited as part of the problem for the economies of Ethiopia, Yemen, Djibouti and others, partly because, as statistics suggest, nearly every family spends one third of its disposable income on Khat.

\section{Methodology}

\subsection{Study Area}

A study was conducted at Sebeta town of Addis Ababa Special Zone, Oromia, Ethiopia, from September to June 2017. Sebeta and its areas are well known in Khat production which is commonly known as 'Bustani Khat', 'Yebole Khat', 'Yegara Khat' and 'Suba-Kersa Khat'. These types of Khat are known with their wide leaf structure and high stimulating capacity. The other type of Khat that is well known in the study area is "Gurage Khat" which it's produced around Gurage Zone and shipped to Sebeta town market.

\subsection{Sampling Procedures}

A random surveying at Khat chewing houses and market place in Sebeta town were done. A total of 250 individuals (i.e. of 242 males and 8 females) were interviewed using 
purposive sampling technique. The data were collected using a structured pre-tested, self-administered questionnaire. The questionnaire was developed based on literature and previously-used questionnaires. The formative assessment identified current issues around Khat use among youth. The questionnaire was prepared and administered in English and Amharic so that participants could choose either language.

\subsection{Statistical Analysis}

The level of significance was calculated with 95\% confidence interval to describe ever and current Khat uses as definedabove. The data were analyzed using descriptive statistics (percentage, tables, minimumand maximum mean values) of socio-demographic and economic variables,friends' characteristics, perceptions about Khat, living arrangements, and family history of Khat use were considered.

\section{Results and Discussions}

\subsection{Household Characteristics}

The results revealed that the ages of respondents are ranged from 19 to 35 years with a mean of 27 years. The family size ranged from a minimum of 1 to a maximum 4, average family size and average active labor force was 2 and 1.5 respectively. The results from table 1 below showed that about $1.6 \%$ of the sample respondents were illiterate, $5.2 \%$ wereable to read and write, $7.6 \%$ weregrade $1-4,5-8$ were $16.8 \%$, grade $9-12$ were $47.2 \%$ and the remaining $21.6 \%$ wereattended college/university level. The study indicated that out of the interviewed sample 64.8\% respondents were Muslims, 31.2\% were Christians and the remaining $4 \%$ were follows other religion. About $62.4 \%$ of the sample respondents were single, about $24.8 \%$ were married, $11.2 \%$ were divorced and the remaining, $1.6 \%$, were widowed (Table 1).

Table 1. The socio-demographic characteristics of the respondents in the town.

\begin{tabular}{lll}
\hline List & Number of Respondents & Percentage \\
\hline Sex & 242 & 97 \\
Male & 8 & 3 \\
Female & & \\
Education & 4 & 1.6 \\
Illiterate & 13 & 5.2 \\
Able to read and write & 19 & 7.6 \\
Grade 1-4 & 42 & 16.8 \\
Grade 5-8 & 118 & 47.2 \\
Grade 9-12 & 54 & 21.6 \\
College/university graduate & \\
Marital Status & & 62.4 \\
Single & 156 & 24.8 \\
Married & 62 & 11.2 \\
Divorced & 28 & 1.6 \\
Widowed & 4 & \\
Religion & & 31.2 \\
Christian & 78 & 64.8 \\
Muslim & 162 & 4 \\
Others & 10 & \\
Family Size & & \\
Mean & 2 & \\
\hline
\end{tabular}

\subsection{Social Impacts of Chewing Khat Among Youth}

The result from the study indicated that, Khat chewing was fairly high with statistically significant associations with sex, religion, family status and income. Majority of the chewers $(47.2 \%)$ were started the habit of Khat chewing in secondary school and followed byat college/university levels and the data indicated that the majorities among the chewersuses other substances together with Khat. The respondents have also reported, spending a significant amount of money and time on Khat chewing and faced health problems they attributed to their habit. In the effort to control the increasing use of Khat amongyouth in Sebeta town should work toward creating awareness on the negative consequences of the practice on health, studies, social interaction and the financial situation toyouth.A total of 250 respondents were invited to participate in these study and completed the prepared questionnaires and included for the analysis of this research. Almost all of the respondents were male (97\%), and Orthodox Christians (31.2\%), Muslim (64.8\%) and others (4\%).Khat chewing occurs more frequently among malesthan females. The peak age of Khat chewing in this study was found to be between 19 and 35 years.

A resultrevealed above indicated thatfrom the youthof Sebeta town that included in the interview were lifetime Khat chewers $(52.3 \%)$. The current popularity rates of Khat chewing were found to be $61.5 \%$. Majority of the youth in Sebeta town started Khat chewing $(47.2 \%)$ while they were senior high school and $21.6 \%$ were started at college/university level.

In the present study, Khat chewing practice showed statistically significant differences with religion which was supported by findings in other studies [8, 9, 17-19]. In addition, the status of Khat chewing was shown to differ in a statistically significant manner in relation to income of the chewer and family which could be associated to the ability to buy Khat and involve in the habit. The data on the pattern of Khat chewing revealed that out of the total 250 respondents who chewed Khat $47.2 \%$, that accounted for the majority, started the practice in high school, and followed by college/university level (21.6\%).

Khat and smoking 'Shisha' are highly increasing in the study area. Majority of the respondents stated that their reason for Khat chewing was because of they are jobless, family case, social case, habit, lack of interest to work and family dependence. The result showed that majority of the Khat chewer interviewed (83.7\%) knew that Khat chewing was a causing factor for mental disorder, gastric, dental and other health problem. Now days the prevalence of cigarette smoking seemed to have decreased among youth, but the prevalence of Khat chewing.

The results of this study revealed that younger peoples attend to follow and support older religious people, if those religious people were chewing Khat and the younger are encouraged to chew Khat. This may be daily practice they try chewing Khat. Later they found themselves as a regular chewer and adapted chewing Khat as usual practice. Respected people in the society 
are the main influencers for Khat chewing. In a certain community people want to confront with social practices and standards and respect the elders and religious people. So they are forced to practice chewing. But the respected people who train others chewing may not know the negative effect of Khat to the life of young people.

In similar manner, the result of the study showed that, among the total chewers in the study area, more than half, $53.2 \%$ reported that as their families were not aware of their habit while the remaining described that it was known by family members. Among chewers whose families were informed of the habit the overwhelming majority, 79.1\% expressed that their families had negatively reacted to habit.

In view of majority of community members in the study area, Khat chewers are less accepted and those people are tried to force the chewers to cease chewing. This social exclusion contributes for family disruption. In family life the expense for buying Khat becomes the cause for conflict of the spouse with the husband as the husband expenses more money for Khat chewing. The chewers also have no adequate time and care for their family.

\subsection{Economic Impacts of Chewing Khat Among Youth}

Khat chewing also affects the economy of the chewers due to the fact that, it leads to loss of working hours or absenteeism from work as well as utilization of money to buy the Khat rather than expensing for buying nutritious foods and care of household members. The present study found the mean time spent for single Khat chewing ceremony was above three hours and the Khat chewers spend different amounts of money on Khat, as well as other items, associated with its consumption such as a cigarette, soft drinks, sugar, 'Shisha'and others. According to the data, more than half $(51.6 \%)$ of the chewers reported spending up to $118.2 \mathrm{ETB}$ per one ceremony on Khat. On the other hand above threefourth, $76.2 \%$ of the chewers mentioned that they spent up to 87.60ETB for other substances taken with or after Khat chewing. The respondents were aware of the common health risks associated with drinking alcohol, smoking cigarette and 'Shisha'but not of chewing Khat. So that the government offices, NGO's and those responsible bodiesshould make an effort to inform or train the youth about the health and socioeconomic problems associated with Khat chewing. They also need counseling on ways of coping with their problems.In this study the risk of Khat chewing, drinking, smoking cigarettes and 'Shisha' were significantly higher among divorced/widowed respondents. This may be because of they used Khat chewing to get temporary relief as well as to forgot the situation due to stimulant effect of the Khat leaves.

\section{Limitations of the Study}

The limitations of the study were, it is done in one location with one season only which may limit to give general recommendation. In addition, because of interview nature of the study, it could offer a chance for interviewer bias. Moreover there is a chance of social desirability bias due to sensitive nature of the issue in the community members as it may enforce the respondents to deny any Khat chewing practices.

\section{Conclusion and Recommendations}

The habit of chewing Khat leaves (Catha edulis Forsk) is widespread in certain areas of East Africa including Ethiopia and the Arabian Peninsula. There are concerns about social, economic and health hazards related to the chewing of Khat. In this study, the effects of Khat chewing were fairly high with statistically significant associations with sex, age, religion, social factor and income. Most of the chewers started the habit in secondary school and college/university levels and the majority among them uses other substances together with Khat. The reports also indicated that to spending a significant amount of money and time on Khat chewing and faced health problems they attributed to their habit. In the effort to control the increasing use of Khat amongyouth in Sebeta town the government should work toward creating awareness on the negative consequences of the practice on health, studies, and financial situation to youth. In addition, the following recommendations for reducing the Khat socio-economic impacts are made for the study area and others:

1) Integrate education and improving public awareness of the potential health problems of Khat chewing and smoking 'Shisha'.

2) Supporting scientific researches on Khat in different Universities and explore the effects of Khat chewing and smoking 'Shisha' on youth's health, social and economy.

\section{Acknowledgements}

I would heartedly like to thank and praise the Lord AlmightyGod in giving us strength and wellbeing to successfully complete the study. I sincerely thank Sebeta town youth and sport office for funding the project.I also want to thanks Kebede Getachew, Dereje W/meskel and Abebe Chaka who helps me in data collection and for all their concern and moral support. Finally,all the reference materials used in this article are dully acknowledged.

\section{References}

[1] Baashar T. The effects of drugs in Islamic World. British Journal of Addiction. 1981; 76:233-43.

[2] Baashar T. The Use of Khat: A stimulant with regional distribution. In: Edwards G, Arif A, editors. Drug Problems in the Sociocultural Context: A Basis for Policies and Programme Planning. Geneva: WHO; 1980.

[3] Abraham D. The impact of long term consumption of Khat on public health. The Sidama Concern. 2000;5 (4):15-16.

[4] Althani IM. In: Development a Saudi Solution for Khat Problem. Khat AlMarzoki H, Abu Khatwa A.N, editors. Jeddah, Mutbouat Publications; 1987. pp. 241-57. 
[5] Halbach H. Medical aspects of the chewing of Khat leaves. Bulletin of the World Health Organization. 1972; 47:21-9.

[6] Lqman W, Donaldson T. The use of Khat (Catha edulis) in Yemen. Social and Medical Observations. Ann Intern Med. 1976; 85:246-9.

[7] Varisco DM. On the meaning of chewing: the significance of Khat (Catha edulis) in the Yemen Arab Republic. International Journal of Middle East Studies. 1986; 18:1-13.

[8] Alem A, Kebede D, Kullgren G. The prevalence and sociodemographic correlates of Khat chewing in Butajira, Ethiopia. Acta Psychiatr Scand Suppl. 1999; 397:84-91.

[9] Kebede Y. Cigarette smoking and Khat chewing among college students, North West Ethiopia. Ethiop J Health Dev. 2002; 16:9-17.

[10] Kebede, A. Alem, G. Mitike et al., "Khat and alcohol use and risky sex behavior among in-school and out-of-school youth in Ethiopia," BMC Public Health, vol. 5, article no. 109, 2005.

[11] Mulugeta, "Khat chewing and its associated factor among college students in Bahir Dar Town, Ethiopia," Science Journal of Public Health, vol. 1, no. 5, pp. 209-214, 2013.

[12] Weir, Qat in Yemen: Consumption and Social Changes, 1985.
[13] Damena, A. Mossie, and M. Tesfaye, "Khat chewing and mental distress: a Community based study, in Jimma, Southwestern Ethiopia," Ethiopian Journal of Health Sciences, vol. 21, no. 1, pp. 37-45, 2011.

[14] Borelli, "Social aspects of drug use in Djibouti: the case of the leaf of Allah," Journal of African Economies, vol. 18, no. 4, pp. 555-591, 2009.

[15] Central Statistical Agency, Ethiopia Demographic and Health Survey 2011, Central Statistical Agency, Addis Ababa, Ethiopia; E.I.I.C., Calverton, Md, USA, 2012

[16] Getahun W, Gedif T, Tesfaye F (2010) Regular khat chewing is associated with elevated diastolic blood pressure among adults in butajira, Ethiopia: a comparative study. BMC public health 10: 390.

[17] Ali WM, Zubaid M, Al-Motarreb A, Singh R, Al-Shereiqi SZ (2010) Association of khat chewing with increased risk of stroke and death with ACS. Mayo Clin Proc 85(11): 974-980.

[18] Jennifer W (2011) Chewing khat linked to stroke and death. Journal of the American Heart association.

[19] Gelaw and Haile-Amlak, "Khat chewing and its sociodemographic correlates among the staff of Jimma University," Ethiopian Journal of Health Development, vol. 18, no. 3, pp. 179-184, 2004. 